\section{Concluding Remarks}

Analyses of gold alloying elements such as copper and zinc found in test solutions (gammaspectrometry), and changes in alloy surface composition (ESCA), after exposure of alloy samples to tarnish solutions are quantitative and in good agreement.

The very initial release rate of copper and zinc from a goldcopper-zinc alloy is the same in magnitude as the release rates from copper and zinc metals. After removal, by constructive selective dissolution, of $\sim 2 \mu \mathrm{g} / \mathrm{cm}^{2}$ copper plus zinc - corresponding to a $\sim 1 \mathrm{~nm}$ thick gold overlayer with the density of metallic gold - the release rate in $0.025 \mathrm{M} \mathrm{NaCl}$ solution is $\sim 1 \mathrm{ng} / \mathrm{cm}^{2}$.h.

Silver-containing low gold alloys ( $\sim 30$ atomic per cent gold) are more sensitive to tarnishing in saliva-like solutions containing sulphide and chloride than low gold alloys with copper or zinc as alloying elements, although both copper and silver sulphides are virtually insoluble. In the saliva-like solutions copper can oxidize to $\mathrm{Cu}_{x} \mathrm{O}_{y}(\mathrm{OH})_{z} \mathrm{Cl}$, with a subsequent chemical dissolution of this type of reaction product. No corresponding pathways of oxidation exist for silver which consequently only oxidizes to insoluble silver sulphide giving rise to tarnish and discolouration of the gold alloy.

The ennoblement (to $\sim 1 \mathrm{~nm}$ ) in the surface of a gold-copperzinc alloy resists some months of exposure to air at room temperature - a time period during which the gold surface composition returns to the nominal bulk value of the alloy. The

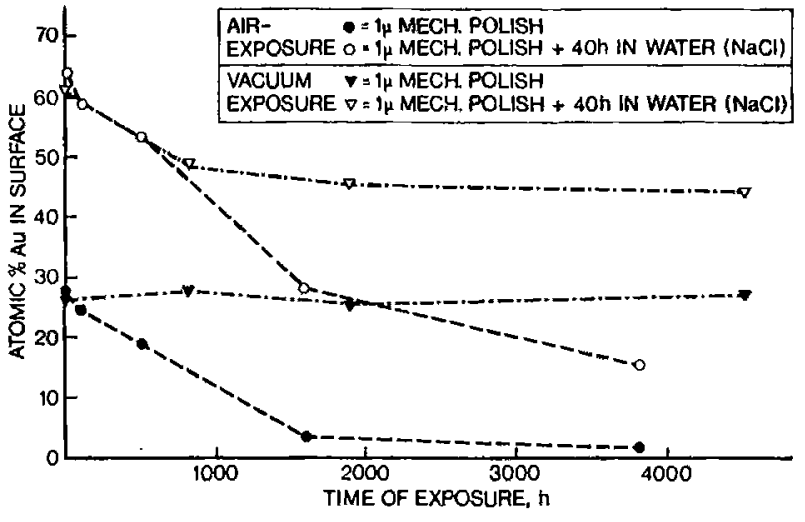

Fig. 6 Gold surface content as measured by ESCA on alloy $A 1$ after exposure in air and vacuum $\left(\mathrm{pO}_{2}<10^{-5} \mathrm{~N} / \mathrm{m}^{2}\right)$ respectively. Nominal $(28 \mathrm{at} . \%)$ and enriched (62 at. \%) gold surface contents were the initial states during the exposures in air and vacuum

main driving force for the diffusion kinetics of this process is oxidation of zinc and copper. Measurement of diffusion at room temperature in a negligible oxidative environment (that is, a vacuum), gives an experimental value of interdiffusion of the order of $10^{-21} \mathrm{~cm}^{2} / \mathrm{s}$ in the surface zone of a gold-copper-zinc alloy.
1 G. Hultquist and C. Leygraf, Mater. Sci. Eng., 1980, 42, 199

2 C. Ingersoll, IADR Program. Abstr. 1975, 54, No. 46

3 G. Hultquist and H. Herd Comos. Sot. 1984, 24, (9), 789-80s

4 D. Brune, B. Forkmann and B. Persson, 'Nuclear Analyric Chemistry' pp. 201, 326. Student Litt, Chartwel!-Bratt Lid., Lund, Sweden 1984

5 D. Brune, G. Hultquist and C. Leygraf, Scand.J. Dent. Res., 1984, No. 3, 262

6 G. Hultquisı. C. Leygraf and D. Brune, J. Electrochem. Soc, 1984, 131, (8) 1773

\section{References}

7 C.C. Chang, Surf. Sci., 1975, 48, 9

8 G. Hulrquist, Article in Dagens Industri, 19th June, 1984 (In Swedish)

9 D.J. Treacy and R.M. German, Gold Bull., 1984, 17, (2), 46

10 H. Hero G. Hulrquist and A. Oden, submitced for publication in Biomater.

II R. Ramstetrer, G. Lampert, A. Seegerand W. Schüle, Pbys. Stat. Sol. 1965, 8. 863

12 H.W. Pickering and C. Wagner, J. Electrochem. Soc, 1967, 114, (7), 698

13 A.J. Forrv, Gold Bull., 1981, 14, (1), 25

\title{
Gold Microelectrodes in Molecule-Based Transistors
}

Three researchers from MIT Department of Chemistry have reported recently (H. Whitc, G.P. Kittlesen and M.S. Wrighton, J. Am. Chem. Soc., 1984, 106, 5375-5377) on the fabrication of a chemically derivatized nicroelectrode array that can function as a transistor when immersed in an electrolyte solution. The key finding is that it can be shown that a small signal (charge) needed to turn on the device can be amplified. The device described mimics the fundamental characteristics of a solid-state transistor, since the resistance between two contacts can be varied by a signal to be amplified. The chemical transistor consists of a set of three (drain, gate and soutce) gold microelectrodes covered with polypyrrole. Three features are essential: (1) the three independent gold microelectrodes are closely spaced, $1.4 \mu \mathrm{m}$ apart, allowing an easily measurable current to pass between the source and drain when drain voltage $V_{D}$ is significant and gate volsage $V_{B}$ is above a threshold value $\mathrm{V}_{\mathrm{r}} ;$ (2) the polypyrole exhibits a sharp change in conductivity upon oxidation; the potential at which this occurs is $\mathrm{V}_{\mathrm{j}} ;(3)$ each of the microelectrodes can be individually contacted. The input signal to the gate to be amplified is that needed to oxidize the polypyrrole, at which potential the polypyrrole switches from insulacing to conducting. The threshold voltage, and the magnitude of signal needed to achieve it, can be altered by variation of the molecule-based material. The transistor reported by White etal. had no immediate practical application at the time of their publication, however the authors point out that considerable interest exists in interfacing microelectronic devices with chemical and biological systems for sensor applications, and in 'molecular electronics' in general. 